\title{
Tingkat Kerawanan dan Mitigasi Bahaya Kebakaran Hutan: Studi Kasus di KHDTK Sawala Mandapa, Kadipaten, Provinsi Jawa Barat (The Level of Vulnerability Forest Fire Hazard Mitigation: Case Study at Sawala Mandapa Forest Research Station (FRS) Kadipaten, West Java Province)
}

\author{
Henny Wahyuti ${ }^{*}$, dan/and Irma Yeny ${ }^{2}$ \\ ${ }^{1}$ Sekolah Menengah Kejuruan Kehutanan Negeri Kadipaten \\ Jl. Raya Timur Sawala Kotak Pos 20 Kadipaten 45452 Kabupaten Majalengka-Jawa Barat \\ Indonesia Telp.: (0233) 661151; Fax: (0233) 664532 \\ ${ }^{2}$ Pusat Penelitian dan Pengembangan Hutan \\ Jl. Gunung Batu No. 5 Bogor 16610 Telp.: (0251) 8633234; \\ Fax: (0251) 8638111, Indonesia \\ "E-mail : wahyutie70@gmail.com
}

Tanggal diterima : 25 Februari 2021; Tanggal direvisi : 16 Agustus 2021; Tanggal disetujui : 22 September 2021

\begin{abstract}
In the dry season, land fires often occur in Sawala Mandapa forest research station (FRS) which is caused by human factors. In terms of anticipating this, the accurate information of land burnt potency is needed. The research aims are to determine the level of fire vulnerability and forest fire hazard mitigation. Data were collected by using survey techniques and interviews with key respondents. The collected data was analyzed in the excel program and showed a factor value of 1 - 5 according to their indicators. A survey was carried out on 11 polygons spread over the Sawala FRS Block 9. The data were collected in the specific form of variables of fire susceptibility level (human activity, land cover, weather, and soil type) and fire mitigation. The results showed that the research area had a vulnerable value of 1.8 - 3.3 (from low to high) vulnerable class category. The low-risk area has forest cover in the form of secondary forest and without any human activities. The moderate vulnerability has forest cover in the form of secondary forest and human activities in the certain forms such as obtaining firewood and community road access. The high vulnerability level has forest cover in the form of secondary forest and has certain human activities such as utilizing land under mahogany and teak stands. In addition, there were indicated that burning activities for waste disposal happened in the area. The mitigation that has been carried out is dominated by non-physical mitigation, namely strengthening community capacity. The fire hazard map produced by this study can be used as the basis for fire prevention policies.
\end{abstract}

Keywords: Human activities, fire susceptibility, forest research station, mitigation

\begin{abstract}
Abstrak
Pada musim kemarau, kebakaran hutan dan lahan sering terjadi di Kawasan Hutan dengan Tujuan Khusus (KHDTK) Sawala Mandapa yang diakibatkan oleh kelalaian manusia. Untuk mengantisipasi hal tersebut, diperlukan informasi yang akurat tentang lahan yang memiliki potensi terbakar. Penelitian ini bertujuan untuk menentukan tingkat kerawanan kebakaran dan mitigasi bahaya kebakaran hutan. Pengumpulan data dilakukan dengan teknik survei dan wawancara terhadap responden kunci. Data yang terkumpul diinput dalam program
\end{abstract}


Microsoft excel dan diberi nilai faktor 1 - 5 sesuai indikator yang dimiliki. Survei dilakukan pada 11 poligon yang tersebar pada KHDTK blok Sawala petak 9. Data yang dikumpulkan berupa variabel tingkat kerawanan kebakaran (aktivitas manusia, tutupan lahan, cuaca dan jenis tanah) dan mitigasi kebakaran. Hasil penelitian menunjukkan bahwa, wilayah penelitian memiliki nilai rawan 1,8 - 3,3 dengan kategori kelas rawan rendah hingga tinggi. Pada areal tingkat rawan rendah memiliki tutupan hutan berupa hutan sekunder dan tidak tampak aktivitas manusia. Tingkat rawan sedang, memiliki tutupan hutan berupa hutan sekunder dan aktivitas manusia berupa pengambilan kayu bakar dan akses jalan masyarakat. Tingkat rawan tinggi memiliki tutupan hutan berupa hutan sekunder dan memiliki aktivitas manusia berupa pemanfaatan lahan di bawah tegakan mahoni dan jati. Selain itu, terdapat aktivitas pembuangan dan pembakaran sampah. Mitigasi yang telah dilakukan didominasi oleh mitigasi non fisik, yaitu penguatan kapasitas masyarakat. Peta kerawanan kebakaran yang dihasilkan penelitian ini dapat dijadikan dasar kebijakan pencegahan kebakaran.

\section{Kata kunci : Aktivitas manusia, kerawanan kebakaran, KHDTK, mitigasi}

\section{Pendahuluan}

Kebakaran hutan merupakan salah satu masalah lingkungan dan kehutanan yang penting dan menjadi perhatian lokal dan global (Cahyono, Warsito, Andayani, \& Darwanto, 2015). Lebih lanjut dikatakan di Indonesia kejadian kebakaran hutan telah terjadi sejak tahun 1978, dan meningkat pada tahun 1982, 1997 dan 2015. Kebakaran hutan dan lahan di Indonesia tahun 2015 merupakan kejadian kebakaran terbesar yang menyebabkan lebih dari 2,6 juta ha hutan terbakar, kerugian ekonomi sekitar \$16 milyar, kerugian lingkungan dan keragaman hayati sekitar \$295 juta (World Bank, 2015). Kebakaran menimbulkan kerugian bagi manusia baik secara ekonomi, sosial, kesehatan, keseimbangan ekosistem, berkurangnya keragaman hayati dan peningkatan emisi karbon yang merupakan ancaman bagi pembangunan berkelanjutan (Miswar, 2020; Pamungkas, 2020). Faktor yang melatarbelakangi kejadian kebakaran dan lahan di Indonesia adalah pembukaan lahan untuk kegiatan ekonomi, meningkatnya sebaran hotspot, pengaruh El-Nino, dan pengeringan lahan gambut melalui kanal yang berlebihan (Septianingrum, 2018).

Upaya pengendalian kebakaran hutan yang sering dilakukan adalah pemadaman kebakaran saat kebakaran terjadi. Upaya ini seringkali tidak optimal terutama pada lahan gambut. (Tata, Narendra, \& Mawazin, 2018). Pengendalian kebakaran hutan akan efektif jika diketahui faktor yang memengaruhi potensi kebakaran (Cahyono et al., 2015).

Oleh karena itu, sangat penting dilakukan perubahan paradigma kebijakan pemadaman menjadi pencegahan munculnya hotspot. Upaya preventif pengendalian jumlah hotspot secara nyata dapat menurunkan kebakaran hutan (Cahyono et al., 2015; Tata et al., 2018). Sebagai upaya preventif pengendalian jumlah hotspot, diperlukan upaya mitigasi, sehingga kebakaran dapat dicegah atau dikurangi baik frekuensi intensitas maupun sebaran kejadian (Rahman \& Yulianti, 2018). Upaya mitigasi kebakaran yang dilakukan dapat menekan dan mengurangi dampak negatif baik secara ekonomi, sosial maupun ekologi (Rahman, 2016). Mitigasi dapat dilakukan dengan dua cara, yaitu secara fisik dan non fisik. Mitigasi fisik merupakan upaya pembangunan infrastruktur untuk meminimalisir resiko bencana, sedangkan mitigasi non fisik merupakan upaya peningkatan kapasitas pemerintah dan masyarakat dalam menghadapi bencana (Rahman, 2016). Salah satu upaya mitigasi fisik dapat dilakukan dengan menyediakan peta daerah kerawanan kebakaran. Peta daerah rawan kebakaran sangat penting dalam membantu 
fire manager dalam mengambil keputusan dalam pencegahan dan pengendalian kebakaran (Tata et al., 2018).

Berbagai metode telah dilakukan untuk menyusun peta daerah rawan kebakaran dan mengetahui faktor yang memengaruhi dan tingkat kerawanan kebakaran pada satu wilayah. Penggunaan software ArcGIS dengan pembobotan pada beberapa parameter menunjukkan bahwa tutupan lahan merupakan faktor yang berpotensi menyebabkan kebakaran lahan (Paulilin, Tjoneng, \& Abdullah, 2017). Untuk memprediksi tingkat kerawanan kebakaran dapat menggunakan metode Fuzzy Tsukomoto yang menghasilkan logika Fuzzy Tsukomoto dalam perhitungan yang sederhana (Ardianto, Haryanto, \& Mulyanti, 2017). Metode K-Medoids clustering memiliki kelebihan dapat mengelompokkan data titik panas dengan nilai Silhouette Coeffient terbaik (Pramesti et al., 2017). Sistem Informasi Geografi (SIG) dan penginderaan jarak jauh merupakan alat yang umum digunakan untuk pemetaan kerentanan kebakaran hutan dan lahan (Nurdiana \& Risdiyanto, 2015).

Indonesia melalui kerja sama bilateral dengan pemerintah Uni Eropa telah membangun sistem informasi kebakaran melalui South Sumantra Forest Fire Management Project (SSFFMP). Sistem yang berbasis SIG ini dapat mendukung dan mengembangkan kapasitas instansi terkait dalam pengumpulan, pengolahan serta penyebaran informasi terkait kebakaran (Solichin et al., 2007). Metode ini membagi kelas kerawanan dengan menggunakan variabel tutupan lahan, tipe lahan dan zona iklim/evelasi.

Pemetaan daerah rawan kebakaran hutan dan lahan yang dikembangkan SSFFMP dapat dimodifikasi dengan mengganti parameter sebaran iklim dengan parameter Fire Weather Index (FWI) dan menambah parameter aktivitas manusia serta perubahan pembobotan (Nugroho, 2019). Lebih lanjut dikatakan FWI digunakan untuk menghitung pengaruh cuaca terhadap potensi kebakaran hutan dan penjalaran kebakaran hutan. FWI juga digunakan untuk mengevaluasi bahaya kebakaran sebagai fungsi dari kondisi cuaca sekarang dan yang lalu. Sementara itu, penambahan parameter aktivitas manusia sangat dibutuhkan karena aktivitas sosial yang tidak terkendali dapat memicu terbentuknya api. Pencegahan dan pengendalian kebakaran hutan dan lahan harus komprehensif dan mencakup dimensi sosial (Tata et al., 2018). Modifikasi metode SSFFMP merupakan cara mengetahui tingkat kerawanan kebakaran dengan memasukkan faktor pemicu dan pendorong kebakaran. Faktor pemicu adalah aktivitas manusia dan kondisi alam. Faktor pendukung meliputi tutupan lahan, riwayat kebakaran, potensi bahan bakar, iklim dan cuaca (Solichin et al., 2007).

Perubahan iklim yang terjadi di wilayah Indonesia telah berdampak menurunnya curah hujan tahunan sebesar 2 - 3\% di wilayah selatan Indonesia dan meningkat di wilayah bagian utara Indonesia (Hairiah \& Sumeru, 2013). Kondisi ini mengakibatkan kawasan hutan salah satunya adalah Kawasan Hutan dengan Tujuan Khusus (KHDTK) Sawala Mandapa cenderung kering dan meranggas pada saat musim kemarau dan berpotensi terjadi kebakaran. Pada tahun 2019 terjadi kebakaran hutan di KHDTK Sawala Mandapa seluas $\pm 3,3$ ha (Dimyati, 2018). Luas lahan yang terbakar relatif kecil, namun kebakaran ini telah berdampak pada berkurangnya tutupan lahan, hilangnya keragaman hayati dan asap yang mengganggu kesehatan. Untuk mencegah terjadinya kebakaran dan mengurangi dampak kebakaran, perlu diketahui tingkat kerawanan kebakaran melalui penyusunan peta kerawanan kebakaran dan mitigasi kebakaran. Penelitian ini bertujuan untuk menentukan tingkat kerawanan kebakaran dan mitigasi bahaya kebakaran hutan. Hasil penelitian ini diharapkan dapat mendukung optimalisasi pencegahan kebakaran hutan. 


\section{Metodologi}

\subsection{Waktu dan Lokasi}

Identifikasi dan pemetaan daerah rawan kebakaran hutan dilaksanakan pada bulan Agustus 2019 - Desember 2019. Lokasi penelitian adalah blok Sawala petak 9 KHDTK Sawala Mandapa (Gambar 1). Secara administrasi lokasi penelitian terletak di Desa Gandasari dan Desa Cipaku Kecamatan Kasokandel Kabupaten Majalengka, Provinsi Jawa Barat.

\subsubsection{Teknik pengumpulan data}

Data yang dikumpulkan terdiri dari data primer dan sekunder. Data primer meliputi kondisi tutupan lahan, potensi bahan bakar, aktivitas penduduk, serta kegiatan mitigasi (pencegahan, pertolongan dan rehabilitasi) yang telah dilakukan pengelola KHDTK Sawala Mandapa. Data sekunder berupa jenis tanah, iklim dan cuaca. Data primer dikumpulkan dengan teknik survei dan wawancara terhadap responden kunci. Responden kunci ditentukan secara sengaja (puspusively), yaitu petugas KHDTK sebanyak tiga orang. Data sekunder diperoleh melalui studi literatur dan pengumpulan data pada instansi terkait. Pengumpulan data dilakukan pada 11 poligon yang tersebar pada blok Sawala petak 9 KHDTK Sawala Mandapa. Data yang terkumpul diinput dalam program excel dan diberi nilai faktor 1 - 5 sesuai indikator yang dimiliki (Tabel $1)$.

\subsubsection{Analisis data}

Data tingkat kerawanan dianalisis secara tabulasi menggunakan program excel dengan rumus penghitungan kerawanan kebakaran menurut Nugroho, (2019) dan dianalisis berdasarkan kelas rawan (Tabel 2).

Tingkat rawan kebakaran $=(0,3 \times$ Tutupan Lahan $)+(0,3 \times$ Aktivitas Masy $)+(0,2 \times$ Cuaca $)+(0,2 \times$ Jenis Tanah $)$

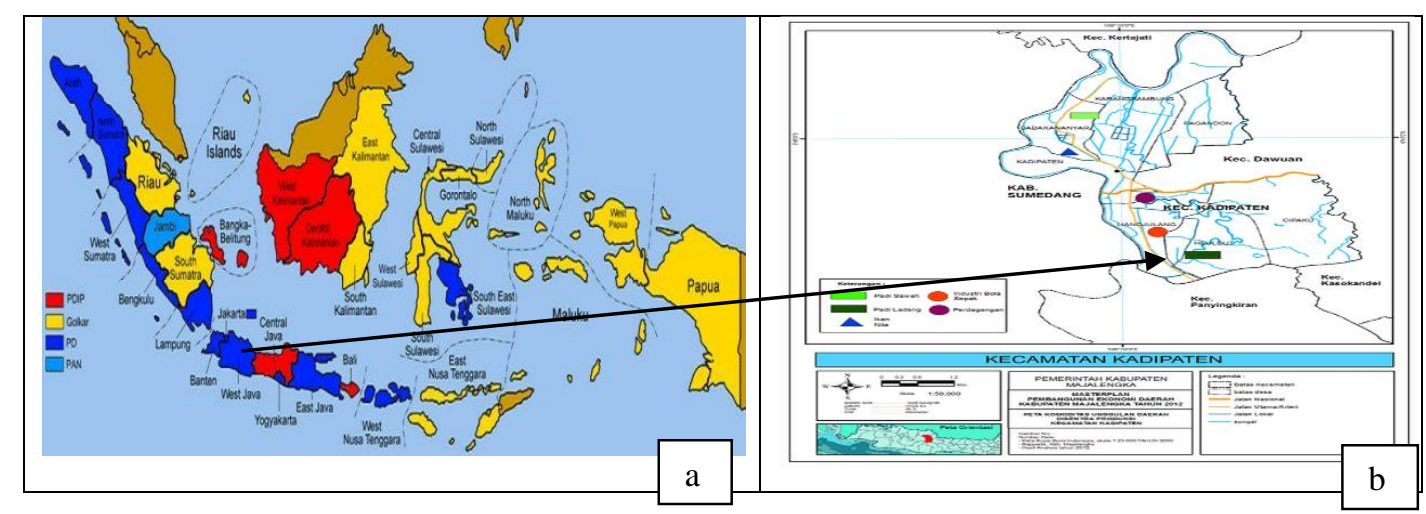

Gambar (Figure) 1. Peta lokasi penelitian: (a) Peta Indonesia dan (b) Peta Kecamatan Kadipaten (Map of research location: (a) Map of Indonesia and (b) Map of Indonesia Kadipaten District) 
Tabel (Table) 1. Nilai faktor berdasarkan parameter (Factor values based on parameters)

\begin{tabular}{|c|c|c|}
\hline $\begin{array}{l}\text { Parameter } \\
\text { (Parameter) }\end{array}$ & Kelas (Class) & Faktor (Factors) \\
\hline Tutupan lahan & Air (Waterbody) & 0 \\
\hline berdasarkan & Awan (Cloud) & 1 \\
\hline tipe vegetasi & Belukar (Shrub) & 3 \\
\hline (Land cover by & Belukar rawa (Swamy shrub) & 5 \\
\hline vegetation & Hutan mangrove primer (Primary mangrove forest) & 1 \\
\hline \multirow[t]{23}{*}{ type) } & $\begin{array}{l}\text { Hutan mangrove sekunder (Secondary mangrove } \\
\text { forest) }\end{array}$ & 2 \\
\hline & Hutan primer (Primary forest) & 1 \\
\hline & Hutan rawa primer (Primer swamp forest) & 2 \\
\hline & Hutan rawa sekunder (Secondary swamp forest) & 3 \\
\hline & Hutan sekunder (Secondary forest) & 2 \\
\hline & Hutan sekunder (Secondary forest) & 2 \\
\hline & Hutan tanaman gambut (Peat plantation forest) & 5 \\
\hline & Hutan tanaman kering (Dry-land plantation forest) & 3 \\
\hline & Pemukiman (Settlement) & 2 \\
\hline & Perkebunan (Plantation) & 3 \\
\hline & Perkebunan karet (Rubber plantation) & 2 \\
\hline & Perkebunan sawit (Palm plantation) & 3 \\
\hline & Perkebunan sawit/karet (Palm/rubber plantation) & 1 \\
\hline & Perkebunan tebu (Sugarcane plantation) & 3 \\
\hline & Perkebunan campuran (Mixed plantation) & 2 \\
\hline & Pertanian lahan kering (Dry land farming) & 3 \\
\hline & Rawa (Swamp) & 5 \\
\hline & Sawah (Rice field) & 2 \\
\hline & Semak rawa (Swamp bush) & 5 \\
\hline & Tambak (Fishpond) & 3 \\
\hline & Tambang (Mine) & 4 \\
\hline & Tanah terbuka (Open ground) & 4 \\
\hline & Transmigrasi (Transmigration) & 2 \\
\hline Aktivitas & Tidak ada (No activity) & 0 \\
\hline masyarakat & Rendah $($ Low $)$ & 2 \\
\hline (Human & Sedang (Medium) & 3 \\
\hline activities) & Tinggi $(H i g h)$ & 5 \\
\hline Cuaca & Rendah (Low) & 2 \\
\hline \multirow[t]{3}{*}{ (Weather) } & Sedang (Medium) & 3 \\
\hline & Tinggi $($ High $)$ & 4 \\
\hline & Ekstrim (Extreme) & 5 \\
\hline Jenis tanah & Bukan gambut ( Mineral) & 1 \\
\hline \multirow[t]{2}{*}{ (Soil type) } & Gambut (Peat) & 5 \\
\hline & Tidak ada data (No data) & 1 \\
\hline
\end{tabular}

Sumber (Source): Nugroho (2019) 
Tabel (Table) 2. Tabel kelas rawan (Vulnerable class table)

\begin{tabular}{clcc}
\hline No. & \multicolumn{1}{c}{$\begin{array}{c}\text { Kelas rawan } \\
\text { (Vulnerable class) }\end{array}$} & Nilai (Score) & Legenda (Legend) \\
\hline 1 & Tidak rawan (Not Prone) & $0-0,99$ & Hijau (Green) \\
2 & Rendah (Low) & $1-1,99$ & Kuning (Yellow) \\
3 & Sedang (Medium) & $2-2,99$ & Orange (Oranye) \\
4 & Tinggi $($ High) & $3-3,99$ & Merah (Red) \\
5 & Sangat rawan $($ Very & $4-5$ & Coklat (Brown) \\
& vulnerable) & & \\
\hline
\end{tabular}

Sumber (Source): Solichin et al. (2007)

Untuk mengetahui kondisi vegetasi dilakukan analisis vegetasi menggunakan parameter $\mathrm{K}=$ Kerapatan (pohon/ha), KR = Kerapatan Relatif (\%), F = Frekuensi $(\%)$, $\mathrm{FR}=$ Frekuensi Relatif $(\%), \mathrm{D}=$ Dominansi $\left(\mathrm{m}^{3} / \mathrm{ha}\right)$, INP $=$ Indeks Nilai Penting $(\%)$ berdasarkan hasil penelitian (Gessa, 2018). Selanjutnya data mitigasi dianalisis dengan mengelompokkan mitigasi berdasarkan parameter mitigasi fisik dan non fisik yang dilakukan (Rahman, 2016). Mitigasi fisik dan non fisik adalah upaya untuk meminimalisir resiko bencana dan dampaknya melalui pembangunan infrastruktur (mitigasi fisik) dan melalui meningkatkan kapasitas pemerintah dan masyarakat dalam menghadapi bencana (non fisik).

\section{Hasil dan Pembahasan}

\subsection{Hasil}

\subsubsection{Biofisik dan kondisi sosial masyarakat di lokasi penelitian}

KHDTK Sawala Mandapa berada di hulu Sub Daerah Aliran Sungai (DAS) Cimanuk-Cilutung. Wilayah ini memiliki topografi datar sampai landai dengan karakteristik lahan seperti pada Tabel 3 dan tutupan lahan seperti pada Tabel 4.
Tabel 3 menunjukkan KHDTK Sawala Mandapa merupakan wilayah dataran rendah yang didominasi topografi datar tersebar di kedua blok, yaitu blok Sawala dan blok Mandapa. Jenis tanah yang mendominasi wilayah ini adalah jenis komplek mediteran, grumosol, dan regosol. Berdasarkan kriteria penetapan hutan lindung, hutan produksi dan hutan konservasi ketiga jenis tanah ini merupakan kelas tanah kurang peka sampai dengan sangat peka terhadap terjadinya erosi (SK Menteri Pertanian No. 683/Kpts/Um/8/81).

Tutupan lahan KHDTK Sawala Mandapa 135,4 ha $(92,4 \%)$ berupa hutan sekunder dengan tanaman serbaguna (MPTS). Kondisi tutupan lahan cukup baik dengan tutupan cukup rapat. Tutupan lahan didominasi oleh pohon jati (T. grandis), disusul johar (S. siamea), Mahoni (S. macrophylla), sengon buto (E. cyclocarpum), sonokeling (D. latifolia), gmelina (G. arborea), kapuk (C. pentandra), bungur (L. floribunda), mangga (M. indica), kesambi (S. oleosa). Hasil perhitungan kerapatan relatif, frekuensi relatif, dominasi relatif dan indeks nilai penting tertinggi vegetasi tingkat pohon di kawasan hutan KHDTK Sawala Mandapa disajikan pada Tabel 5. 
Tabel (Table) 3. Karakteristik lahan KHDTK Sawala Mandapa (Land of characteristics at KHDTK Sawala Mandapa)

\begin{tabular}{|c|c|c|c|}
\hline Uraian (Analysis) & $\begin{array}{c}\text { Luas (Large) } \\
(\mathrm{Ha})\end{array}$ & $\begin{array}{c}\text { Luas } \\
\text { (Large) } \%\end{array}$ & Lokasi (Locate) \\
\hline 1. Kelas lereng (Slopes class) & & & \\
\hline a. $0-8 \%$ Datar (Flat) & 118,55 & 81,34 & $\begin{array}{l}\text { blok Sawala dan } \\
\text { Mandapa }\end{array}$ \\
\hline b. $8-15 \%$ Landai (Sloping) & 27,20 & 18,66 & $\begin{array}{l}\text { blok Sawala dan } \\
\text { Mandapa }\end{array}$ \\
\hline c. $15-25 \%$ Agak curam (A bit stape) & 0 & 0 & - \\
\hline $\begin{array}{l}\text { 2. Ketinggian tempat (Altitude) (mdpl) } \\
\text { a. 67-72 Dataran rendah (Low land) }\end{array}$ & 146 & 100 & $\begin{array}{l}\text { blok Sawala dan } \\
\text { Mandapa }\end{array}$ \\
\hline b. Dataran tinggi (Plateau) & 0 & 0 & - \\
\hline $\begin{array}{l}\text { 3. Jenis tanah (Type of soil) } \\
\text { a. Alluvial (Alluvial) } \\
\text { b. Komplek Gramusol, regosol dan } \\
\text { mediteran (Grumusol complex, } \\
\text { regosol and mediteran) }\end{array}$ & $\begin{array}{l}53,14 \\
92,86\end{array}$ & $\begin{array}{l}36,4 \\
63,6\end{array}$ & $\begin{array}{l}\text { blok Mandapa } \\
\text { blok Sawala }\end{array}$ \\
\hline
\end{tabular}

Tabel (Table) 4. Tutupan lahan KHDTK Sawala Mandapa Kadipaten (Land cover of KHDTK Sawala Mandapa Kadipaten)

\begin{tabular}{lr}
\multicolumn{1}{c}{ Tutupan lahan (Land cover) } & \multicolumn{1}{c}{$\begin{array}{c}\text { Luas proporsi } \\
\text { (Area of proportion })(\mathrm{Ha})\end{array}$} \\
\hline 1. Area parkir (Parking area) & 0,187 \\
2. Bangunan (Building) & 7,570 \\
3. Tegakan bungur (Stands of Lagerstroemia & \\
$\quad$ floribunda Jack.) & 1,264 \\
4. Tegakan cendana (Stands of Santalum album & \\
L.) & 0,387 \\
5. Embung/Danau/Kolam (Lake) & 1,107 \\
6. Tegakan jati (Stands of Tectona grandis L.f.) & 34,498 \\
7, Tegakan johar (Stands of Senna siamea & \\
(Lam.) H.S.Irwin \& Barneby) & 27,535 \\
8. Tegakan kesambi (Stands of Schleichera oleosa & \\
(Lour.) Okens) & 14,068 \\
9. Tegakan kaya (Stand of Khaya & \\
anthoteca (Welw.) C.DC.) & 0,952 \\
10. Lapangan kosong (Field) & 0,487 \\
11. Tegakan mahoni (Stands of Swietenia & \\
$\quad$ mahagoni King.) & 14,890 \\
12. Areal makam (Tomb area) & 1,257 \\
13. MPTS (Multy Purpose Tree Species) & 2,640 \\
14. Tegakan nyamplung (Stands of Calophyllum & \\
inophyllum L.) & 0,883 \\
\hline
\end{tabular}


Lanjutan (Continue)

\begin{tabular}{lc}
\hline \multicolumn{1}{c}{ Tutupan lahan (Land cover) } & $\begin{array}{c}\text { Luas proporsi } \\
\text { (Area of proportion) (Ha) }\end{array}$ \\
\hline 15. Areal persemaian (Nursery area) & 0,602 \\
\hline 16. Tegakan sengon buto (Stands of & 1,886 \\
Enterolobium cyclocarpum Griseb.) & \\
17. tegakan sonokeling (Stands of Dalbergia & 18,119 \\
latifolia Roxb, ex Sm.) & 18,249 \\
18.Tegakan campuran (Mixed stands) & 146,580 \\
\hline Total
\end{tabular}

Sumber (Source): Data Primer (2019)

Tabel (Table) 5. Indeks nilai penting pohon di KHDTK Sawala Mandapa (Tree importance index in KHDTK Sawala Mandapa)

\begin{tabular}{llccccccc}
\hline No & \multicolumn{1}{c}{ Jenis (Species) } & K & KR $(\%)$ & F & FR (\%) & D & DR (\%) & INP \\
\hline 1 & Jati (T. grandis) & 382,61 & 36,36 & 0,65 & 31,91 & 30,87 & 29,24 & 97,52 \\
2 & Johar (S. siamea) & 334,78 & 31,82 & 0,57 & 27,66 & 29,78 & 28,21 & 87,69 \\
3 & Mahoni (S. macrophylla) & 173,91 & 16,53 & 0,30 & 14,89 & 12,83 & 12,15 & 43,57 \\
& & & & & & & \\
4 & Sengon (F. Falcata) & 91,30 & 8,68 & 0,13 & 6,38 & 19,13 & 18,12 & 33,18 \\
5 & Sonokeling (D. latifolia) & 26,09 & 2,48 & 0,13 & 6,38 & $2, .96$ & 2,80 & 11,66 \\
& & & & & & & & \\
6 & Gmelina (G. arborea) & 26,09 & 2,48 & 0,09 & 4,26 & 4,13 & 3,91 & 10,65 \\
& & & & & & & \\
7 & Kapuk (C. pentandra) & 4,35 & 0,41 & 0,04 & 2,13 & 3,57 & 3,38 & 5,92 \\
8 & Bungur (L. floribunda) & 4,35 & 0,41 & 0,04 & 2,13 & 1,52 & 1,44 & 3,98 \\
& & & & & & & & \\
9 & Mangga (M. indica) & 4,35 & 0,41 & 0,04 & 2,13 & 0,48 & 0,45 & 2,99 \\
& Kesambi (S. oleosa) & 4,35 & 0,41 & 0,04 & 2,13 & 0,30 & 0,29 & 2,83 \\
\hline
\end{tabular}

Sumber (Source): Gessa (2018)

Tabel (Table) 6. Data curah hujan Majalengka tahun 2011-2020 (Majalengka rainfall data of Majalengka for 2011-2020)

\begin{tabular}{|c|c|c|c|c|c|c|c|c|c|c|c|c|}
\hline \multirow{2}{*}{$\begin{array}{l}\text { Tahun } \\
\text { (Year) }\end{array}$} & \multicolumn{12}{|c|}{ Curah hujan ( mm) (Rainfall) } \\
\hline & Jan & Feb & Maret & April & Mei & Juni & Juli & Agust & Sept & Okt & Nov & Des \\
\hline 2011 & 76,8 & 181,7 & 566,9 & 612,3 & 142,2 & 97,7 & 0,0 & 0,0 & 0,0 & 40,1 & 393,8 & 471,1 \\
\hline 2012 & 470,0 & 258,0 & 362,0 & 153,0 & 56,0 & 75,0 & 0,0 & 44,0 & 0,0 & 47,0 & 220,0 & 494,0 \\
\hline 2014 & 592,0 & 343,0 & 223,0 & 300,0 & 196,0 & 54,0 & 62,0 & 9,0 & 0,0 & 18,0 & 233,0 & 442,0 \\
\hline 2015 & 426,0 & 380,0 & 327,0 & 301,0 & 99,0 & 0,0 & 1,0 & 0,2 & 0,5 & 0,0 & 94,9 & 420,3 \\
\hline 2018 & 122,4 & 495,6 & 682,7 & 359,2 & 96,7 & 32,2 & 682,7 & 0,0 & 1,0 & 7,5 & 150,9 & 201,2 \\
\hline 2019 & 266,2 & 441,0 & 297,5 & 367,7 & 125,6 & 0,0 & 0,0 & 0,0 & 0,0 & 0,0 & 68,3 & 383,7 \\
\hline 2020 & 405,6 & 462,2 & 399,2 & 361,5 & 192,8 & 41,3 & 62,6 & 20,0 & 48,5 & 237,4 & 498,5 & 496,7 \\
\hline Rata-rata & 379,43 & 362,56 & 430,86 & 317,45 & 131,16 & 75,48 & 109,73 & 18,22 & 23,98 & 104,6 & 264,58 & 357,15 \\
\hline
\end{tabular}

Sumber (Source): BMKG Jatiwangi (2021)

Hasil perhitungan curah hujan dalam 10 tahun terakhir (2011 - 2020) menunjukkan perbandingan bulan kering dengan bulan basah menunjukkan nilai $\mathrm{Q}=$ 0,22. Berdasarkan klasifikasi iklim Schmidt-Ferguson masuk dalam kategori B (basah). Hutan Diklat Sawala Mandapa dikelilingi dan berbatasan langsung dengan delapan desa, yaitu Desa Cipaku Kecamatan Kadipaten, Desa Genteng, Bojong Cideres, Sinarjati, Dauan Kecamatan Dauan, Desa Gunung Sari dan Gandasari Kecamatan Kasokandel. Desa Dauan memiliki tingkat kepadatan 
penduduk tertinggi, sedangkan Desa Cipaku Kecamatan Kadipaten merupakan desa dengan kepadatan terendah. Laju pertumbuhan pada semua desa berada pada kategori lambat (rendah) $<1 \%$ setiap tahunnya. Masyarakat sekitar KHDTK Sawala Mandapa memiliki mata pencaharian utama sebagai Pegawai Negeri Sipil (PNS), TNI/POLRI, Petani, Buruh, Wiraswasta, dan lain-lain. Selain mata pencaharian utama, masyarakat sekitar hutan memiliki aktivitas sampingan mencari kayu bakar, merumput dan juga bertani. Beberapa petani menggunakan pola agroforestri dengan mengombinasikan tanaman tahunan, seperti mahoni, jati dengan tanaman obat-obatan dan tanaman palawija. Di sekitar KHDTK Sawala Mandapa juga terdapat kelompok tani yang melakukan budi daya tanaman porang serta budi daya tanaman palawija, seperti kunyit, cabai, jagung, oyong, kacang panjang sebagai komoditas kelola usahanya. Petani tersebut juga melakukan pemeliharaan ternak, seperti domba dan ayam kampung.

Penduduk memiliki aktivitas yang berbeda-beda pada setiap poligon. Pada poligon 9 dan 10 aktivitas penduduknya sangat tinggi karena penduduk melakukan aktivitas pembuangan dan pembakaran sampah di poligon tersebut (Gambar 2).

\subsubsection{Tingkat kerawanan kebakaran}

Berdasarkan perhitungan faktor di setiap poligon, maka wilayahnya termasuk kelas rawan dengan nilai rawan kebakaran berkisar 1,8 - 3,3 (kelas rawan rendah, sedang dan tinggi) (Tabel 7).

Tingkat kerawanan kebakaran pada areal KHDTK Sawala Mandapa menunjukkan potensi terjadinya kebakaran dengan tingkat kelas rawan rendah sampai tinggi. Kelas rawan rendah pada poligon 1, 2 dan 3 dan kelas rawan sedang berada pada enam poligon, yaitu poligon 4, 5, 6, 7, 8 dan 11. Kelas rawan tinggi berada pada dua poligon, yaitu poligon 9 dan 10. Semua poligon memiliki cuaca ekstrim dan jenis tanah mineral atau bukan gambut. Tutupan lahan terdiri hutan sekunder yang ditumbuhi berbagai jenis pohon yang berbeda tiap poligon. Perbedaan antar poligon terlihat pada aktivitas manusia, dimana terdapat bentuk pemanfaatan lahan dari rendah sampai tinggi. Aktivitas manusia yang tinggi memberi kontribusi yang besar pada tingkat kerawanan suatu wilayah. Data kelas rawan dapat digambarkan dalam peta tingkat kerawanan kebakaran (Gambar 3).

\subsubsection{Mitigasi kebakaran}

Upaya mitigasi kebakaran di wilayah KHDTK Sawala Mandapa dilakukan dalam bentuk mitigasi fisik dan non fisik (Tabel 8). Pelaksanaan kegiatan mitigasi mengacu pada Peraturan Menteri LHK Nomor P.32 tahun 2016 tentang Pengendalian Kebakaran Hutan dan Lahan.

Tabel 8 menunjukkan sebagian besar kegiatan penanganan bencana kebakaran dilakukan dalam bentuk mitigasi (71\%). Mitigasi tersebut terdiri dari $40 \%$ mitigasi fisik dan $60 \%$ mitigasi non fisik. Mitigasi fisik didominasi oleh bangunan dan peralatan yang digunakan pada saat kejadian kebakaran. Peralatan dan bangunan yang digunakan dalam rangka pencegahan masih sangat terbatas. 
Tabel (Table) 7. Perhitungan nilai rawan kebakaran berdasarkan data FWI (Calculation of fire hazard values based on FWI data)

\begin{tabular}{ccccccc}
\hline $\begin{array}{c}\text { Poligon } \\
\text { (Poligon) }\end{array}$ & $\begin{array}{c}\text { Tutupan } \\
\text { lahan } \\
\text { (Land } \\
\text { Cover) }\end{array}$ & $\begin{array}{c}\text { Aktivitas } \\
\text { manusia } \\
\text { (Human } \\
\text { activities })\end{array}$ & $\begin{array}{c}\text { Cuaca } \\
\text { (Wheater }\end{array}$ & $\begin{array}{c}\text { Jenis } \\
\text { tanah } \\
\text { (Soil } \\
\text { type) }\end{array}$ & $\begin{array}{c}\text { Nilai rawan } \\
\text { kebakaran (Fire } \\
\text { hazard values) }\end{array}$ & $\begin{array}{c}\text { Kelas rawan } \\
\text { (Hazard class) }\end{array}$ \\
\hline 1 & 2 & 0 & 5 & 1 & 1,8 & Rendah (Low) \\
2 & 2 & 0 & 5 & 1 & 1,8 & Rendah (Low) \\
3 & 2 & 0 & 5 & 1 & 1,8 & Rendah (Low) \\
4 & 2 & 2 & 5 & 1 & 2,4 & Sedang (Middle) \\
5 & 2 & 3 & 5 & 1 & 2,7 & Sedang (Middle) \\
6 & 2 & 5 & 5 & 1 & 2,9 & Sedang (Middle) \\
7 & 2 & 3 & 5 & 1 & 2,7 & Sedang (Middle) \\
8 & 2 & 5 & 5 & 1 & 2,7 & Sedang (Middle) \\
9 & 2 & 5 & 5 & 1 & 3,3 & Tinggi (High) \\
10 & 2 & 5 & 5 & 1 & 3,3 & Tinggi (High) \\
11 & 2 & 3 & 5 & 1 & 2,7 & Sedang (Middle) \\
\hline
\end{tabular}

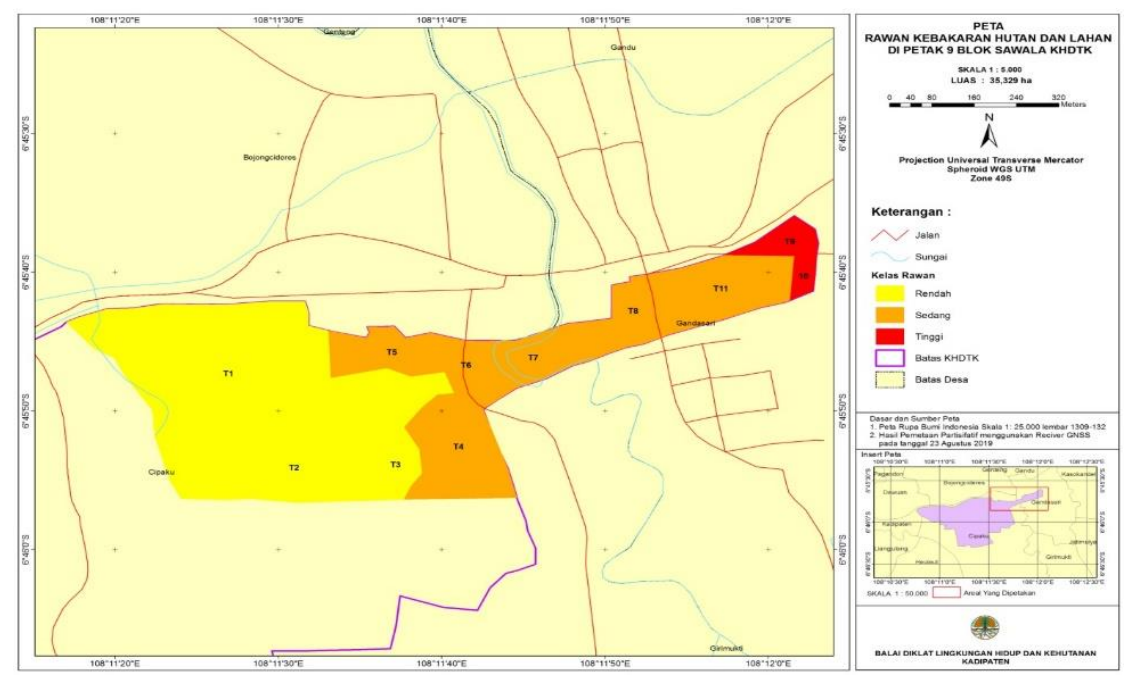

Gambar (Figure) 3. Peta rawan kebakaran hutan blok Sawala Petak 9 KHDTK Sawala Mandapa Kadipaten (Forest fire hazards map of Sawala block at KHDTK Sawala Mandapa Kadipaten) 
Tabel (Table) 8. Penanganan kebakaran hutan di KHDTK Sawala Mandapa (Mitigation of forest fires at KHDTK Sawala Mandapa)

\begin{tabular}{|c|c|c|c|c|}
\hline No. & & Uraian (Description) & $\begin{array}{l}\text { Mitigasi fisik } \\
\text { (Physical } \\
\text { mitigation) } \\
\end{array}$ & $\begin{array}{l}\text { Mitigasi non fisik } \\
\text { (Non-physical } \\
\text { mitigation })\end{array}$ \\
\hline \multirow[t]{11}{*}{ A. } & & $\begin{array}{l}\text { Mitigasi dalam pencegahan kebakaran } \\
\text { (Mitigation in fire prevention) }\end{array}$ & - & \\
\hline & 1 & $\begin{array}{l}\text { Sosialisasi dan penyuluhan (Socialization } \\
\text { and counseling) }\end{array}$ & - & $\mathrm{V}$ \\
\hline & 2 & $\begin{array}{l}\text { Himbauan dan pemasangan panfet } \\
\text { karhutla (Appeal and installation of forest } \\
\text { and land fire pamphlet) }\end{array}$ & - & $\mathrm{V}$ \\
\hline & 3 & $\begin{array}{l}\text { Pelibatan masyarakat dalam } \\
\text { memanfaatkan lahan di bawah tegakan } \\
\text { (Community involvement in utilizing land } \\
\text { under stands) }\end{array}$ & - & $\mathrm{V}$ \\
\hline & 4 & $\begin{array}{l}\text { Pendampingan anggota kelompok tani } \\
\text { hutan sebagai masyarakat peduli api } \\
\text { (Assistance for members of forest farmer } \\
\text { groups as fire-aware communities) }\end{array}$ & - & $\mathrm{V}$ \\
\hline & 5 & $\begin{array}{l}\text { Pelatihan pembukaan lahan tanpa bakar } \\
\text { (Making firebreaks) }\end{array}$ & - & $\mathrm{V}$ \\
\hline & 6 & $\begin{array}{l}\text { Persiapan alat, bahan dan transportasi } \\
\text { pemadaman (Preparation of extinguishing } \\
\text { tools, materials and transportation) }\end{array}$ & $\mathrm{V}$ & - \\
\hline & 7 & $\begin{array}{l}\text { Pembuatan sekat bakar (Making } \\
\text { firebreaks) }\end{array}$ & $\mathrm{V}$ & - \\
\hline & 8 & Pembuatan embung (Pon construction) & $\mathrm{V}$ & - \\
\hline & 9 & $\begin{array}{l}\text { Pemasangan rambu-rambu peringatan } \\
\text { kebakaran (Installation of fire warning } \\
\text { signs) }\end{array}$ & $\mathrm{V}$ & - \\
\hline & 10 & $\begin{array}{l}\text { Patroli kebakaran hutan (Forest fire } \\
\text { patrol) }\end{array}$ & - & $\mathrm{V}$ \\
\hline \multirow[t]{4}{*}{ B. } & & Pengendalian kebakaran (Fire control) & & \\
\hline & 1 & Pemadaman api (Fire fighting) & $\mathrm{V}$ & - \\
\hline & 2 & $\begin{array}{l}\text { Komunikasi dengan pihak terkait } \\
\text { (Communication with related parties) }\end{array}$ & - & $\mathrm{V}$ \\
\hline & 3 & $\begin{array}{l}\text { Patroli sampai api dapat dikendalikan } \\
\text { (Patrol until the fire is under control) }\end{array}$ & - & $\mathrm{V}$ \\
\hline \multirow[t]{2}{*}{ C. } & & $\begin{array}{l}\text { Pasca kebakaran (Post-fire patrol until the } \\
\text { fire is under control) }\end{array}$ & & \\
\hline & 1 & $\begin{array}{l}\text { Memulihkan vegetasi hutan dengan } \\
\text { melibatkan masyarakat dalam penanaman } \\
\text { pada areal bekas kebakaran (Restoring } \\
\text { forest vegetation by involving the } \\
\text { community in planting in burnt areas) }\end{array}$ & V & - \\
\hline
\end{tabular}




\subsection{Pembahasan}

\subsubsection{Tingkat kerawanan kebakaran}

Hasil penelitian yang dilakukan di 11 poligon yang tersebar pada blok Sawala petak 9 KHDTK Sawala Mandapa Kadipaten menunjukkan terdapat kelas rawan rendah hingga tinggi. Kelas rawan rendah pada poligon 1, 2, 3 dan areal tersebut ditemui aktivitas masyarakat. Kondisi tutupan lahan tampak rapat berupa hutan sekunder yang terdiri atas tegakan bungur (Lagerstroemia sp.), mahoni daun besar (S. macrophylla), bambu (Bambusa sp.), flamboyan (D. regia), jati (T. grandis), nangka (A. heterophyllus), sukun (A. altilis), mangga (Mangifera sp.), kopi (Coffea sp.). Jenis jati mendominasi pada tingkat pohon dan tiang dengan nilai INP berturut-turut 97,52 dan 115,26. Pada tingkat pancang dan semai didominasi jenis mahoni (S. macrophylla) dengan nilai INP berturut turut 66,80 dan 88,18 (Gessa, 2018). Area tidak terbakar didominasi dengan nilai kerapatan tinggi dibandingkan dengan area yang tidak terbakar (Rachman et al., 2020).

Kelas rawan sedang pada poligon 4, 5, $6,7,8$ dan 11 , terlihat adanya aktivitas penduduk pada tingkat sedang, berupa pemanfaatan kayu bakar, merumput dan terdapat jalan desa yang biasa dilalui oleh masyarakat. Aktivitas masyarakat dapat menjadi faktor pemicu terjadinya kebakaran (Solichin et al., 2007). Pemicu kebakaran dapat terjadi berupa api yang berasal dari korek api dan puntung rokok yang dibuang oleh pejalan kaki maupun pengendara di sepanjang jalan tersebut. Poligon dengan kelas rawan sedang memiliki tutupan lahan berupa hutan sekunder yang tidak terlalu rapat. Jenis yang banyak ditemui adalah mahoni daun besar (S. macrophylla), sonokeling (D. Latifolia) dan bungur (Lagerstroemia sp.). Nilai kerapatan masing-masing jenis berturut-turut 173,91, 26,09 dan 4,35 (Gessa, 2018).

Kelas rawan tinggi terdapat pada poligon 9 dan 10, dimana areal tersebut adanya aktivitas masyarakat yang tinggi dan berbatasan dengan pemukiman penduduk. Terdapat aktivitas budi daya tanaman di bawah tegakan mahoni macrophylla) serta tempat pembuangan dan pembakaran sampah. Aktivitas manusia dalam usaha pemanfaatan lahan dapat menjadi ancaman sekaligus sebagai pencegah terjadinya kebakaran hutan dan lahan (Jawad et al., 2015). Tutupan lahan berupa hutan sekunder yang didominasi tegakan jati (T. grandis), mahoni daun besar (S. macrophylla), bambu (Bambusa sp), sonokeling (D. latifolia) dan tanaman MPTS, yaitu sukun (A. altilis), mangga (Mangifera sp.), kopi (Coffea sp.), nangka (A. heterophyllus). Pada bulan kering Juni sampai Oktober dimana curah hujan ratarata berkisar 23,98 - 109,73 $\mathrm{mm} /$ bulan, tanaman jati (T. grandis) dan mahoni daun besar (S. macrophylla) akan mengugurkan daun untuk mengurangi penguapan sehingga akan terjadi penumpukan daun kering pada lantai hutan. Jumlah serasah kering pada poligon 9 dan 10 lebih banyak dibandingkan pada poligon lainnya. Rachmawati dan Susilawati (2012) menyatakan bahan bakar berupa bagian tanaman dalam keadaan kering dapat terbakar dan menghasilkan panas yang tinggi, sedangkan bahan bakar berupa rumput dan serasah dapat terbakar lebih cepat dan menyebabkan kebakaran yang lebih luas. Tingkat kepekaan bahaya kebakaran hutan juga terjadi pada lahan terbuka berupa tegalan dan semak. Hal ini karena areal tersebut memiliki kelembapan yang rendah dan mengandung bahan bakar kering (Viviyanti, Adila, \& Rahmad, 2019).

Hasil penelitian ini menunjukkan bahwa nilai ambang batas kerawanan kebakaran berada pada kelas rawan tinggi sampai sangat tinggi dengan nilai kelas rawan dengan interval 3 - 5. Ambang batas kerawanan terlihat pada aktivitas manusia sangat tinggi, tutupan lahan berupa hutan sekunder dengan kerapatan rendah dan curah hujan rendah. 
Aktivitas manusia yang menjadi ambang batas kerawanan kebakaran adalah open acces kawasan hutan. Open access menjadi salah satu faktor pemicu terjadinya kebakaran (Tata et al., 2015). Mapilata, Gandasasmita, \& Djajakirana (2013) menyebutkan bahwa pada kawasan hutan yang digunakan menjadi areal budi daya dengan aktivitas tinggi berpeluang terjadinya kebakaran hutan dan lahan. Faktor kelalaian manusia akibat melakukan pembakaran dalam mengolah atau membersihkan lahan garapannya merupakan potensi terjadinya kebakaran (Nursoleha, Banowati, \& Parman, 2014).

Tutupan hutan yang menjadi ambang batas tingkat rawan tinggi sampai sangat tinggi, terlihat pada tutupan hutan yang tidak rapat dan didominasi oleh beberapa jenis pohon yang menggugurkan daun di musim kemarau. Pohon jati (T. grandis) dan mahoni daun besar (S. macrophylla) pada musim kemarau menggugurkan daun, sementara tumbuhan lainnya menjadi mati dan mengering. Pohon yang mati masih berdiri dan sudah mengering menjadi bahan bakar yang potensial. Lantai hutan yang datar dan dipenuhi dengan ranting kering dan serasah akan memudahkan penjalaran api, sehingga akan memperluas areal yang terbakar dan sulit untuk dipadamkan.

Curah hujan yang menjadi ambang batas terjadi pada bulan Juni - Oktober dengan interval curah hujan 23,98 - 109,73 $\mathrm{mm} /$ bulan. Nilai ambang batas curah hujan ini tidak berbeda jauh dengan hasil penelitian Itsnaini, Sasmito, Sukmono, \& Prasasti (2017), yang menyebutkan nilai ambang batas curah hujan 30 hari sebelum kebakaran sebesar 0,00 - 174,615 mm. Bulan Juni sampai Oktober merupakan musim kemarau dengan puncaknya di bulan Agustus, sehingga memicu terjadi kebakaran di beberapa wilayah, salah satunya di kawasan Taman Nasional Gunung Ciremai (Nursoleha et al., 2014). Wilayah yang memiliki curah hujan rendah berpotensi sebagai pusat panas yang dapat menyebabkan kebakaran hutan dan lahan
(Humam, Hidayat, Nurrochman, Anestatia, Yuliantina, \& Aji, 2020). Syaufina dan Hafni (2018) menyebutkan adanya hubungan antara unsur iklim dengan distribusi titik panas dimana hubungan curah hujan dengan jumlah titik panas berbanding terbalik. Itsnaini et al., (2017) menyatakan bahwa curah hujan dapat digunakan sebagai indikasi potensi untuk terjadinya kebakaran hutan dan lahan. Suatu wilayah yang memiliki curah hujan tinggi akan menyebabkan tingginya kadar air bahan bakar yang akan mempersulit terjadinya kebakaran. Namun sebaliknya jika curah hujan rendah dengan suhu yang tinggi atau perubahan cuaca akan menurunkan kadar air bahan bakar sehingga kebakaran mudah terjadi. Kebakaran di Kalimantan dan Sumatera pada bulan Oktober 1982 - April/Mei 1983 (delapan bulan), dan tahun-tahun 1987, 1991, 1994, 1997 diduga sebagai akibat kecerobohan manusia dalam menggunakan api, serta karena banyaknya sumber api. Faktor pemicu pada kejadian kebakaran hutan dan lahan di Kota Palangka Raya adalah aktivitas manusia (Mapilata et al., 2013).

\section{Kesimpulan dan Saran}

\subsection{Kesimpulan}

Tingkat kerawanan kebakaran di areal KHDTK Sawala Mandapa bervariasi dari rendah sampai tinggi dengan nilai 1,8 - 3,3. Ambang batas kerawanan terlihat pada aktivitas manusia sangat tinggi, tutupan lahan berupa hutan sekunder dengan kerapatan rendah dan curah hujan rendah. Nilai ambang batas kerawanan kebakaran berada pada kelas rawan tinggi sampai sangat tinggi dengan nilai kelas rawan interval 3 - 5. Untuk menyelesaikan permasalahan kebakaran hutan diperlukan upaya mitigasi baik mitigasi fisik maupun non fisik. Upaya mitigasi non fisik melalui peningkatan kapasitas masyarakat harus didukung dengan pengetahuan wilayah yang memiliki tingkat kerawanan tinggi. Penggunaan informasi peta kerawanan 
kebakaran di setiap wilayah merupakan bentuk mitigasi fisik dalam upaya penyelesaian permasalahan kebakaran hutan. Peta daerah rawan kebakaran merupakan dasar pertimbangan dalam perencanaan pencegahan kebakaran hutan dan lahan, Selain itu, sebagai upaya pencegahan yang lebih terarah, efektif dan efisien, sehingga tingkat resiko terjadinya bahaya kebakaran dapat diketahui lebih dini.

\subsection{Saran}

Pengelola KHDTK Sawala Mandapa perlu menghitung tingkat kerawanan kebakaran pada seluruh areal hutan sekunder. Hasil perhitungan yang dituangkan dalam bentuk peta dapat digunakan sebagai dasar perencanaan pembinaan masyarakat dan pembangunan sarana fisik pengendalian kebakaran.

\section{Ucapan Terima Kasih}

Penulis mengucapkan terima kasih kepada BDLHK Kadipaten khususnya KHDTK Sawala Mandapa, BMKG Jatiwangi dan pihak SMK Kehutanan Negeri Kadipaten yang telah membantu selama pengumpulan data dan proses penulisan naskah ini.

\section{Daftar Pustaka}

Ardianto, C., Haryanto, H., \& Mulyanto, E. (2017). Prediksi tingkat kerawanan kebakaran di daerah Kudus menggunakan Fuzzy Tsukamoto. Citec Journal, 4(3), 186-194.

BMKG Jatiwangi. (2021). Data Curah Hujan Majalengka Tahun 2011-2020.

Cahyono, A., Warsito, S.P., Andayani, W., \& Darwanto, D. (2015). Faktor yang mempengaruhi kebakaran hutan di Indonesia dan implilasi kebijakannya. Jurnal Sylva Lestari, 3(1), 103-112.

Dimyati. (2018). Pengembangan Hutan Diklat Sawala Mandapa. Kadipaten:
Sawala Press.

Gessa, G. (2018). Potensi KHDTK Sawala Mandapa Tahun 2018. Prosiding Seminar Jabatan Fungsional Tertentu Tema Pembangunan Lingkungan Hidup Dan Kehutanan Dan Sumber Daya Manusia Pengelolanya Di Kadipaten. Kadipaten 8 September 2018.

Hairiah, K., \& Sumeru, A. (2013). Pertanian masa depan: Agroforestri, manfaat dan layanan lingkungan. Prosiding Seminar Nasional Agroforetri "Agroforestri untuk Pangan dan Lingkungan yang Lebih Baik" Malang, 21 Maret 2013, 23-35.

Humam, A., Hidayat, M., Nurrochman, A., Anestatia, I., Yuliantina, A., \& Aji, S. (2020). Identifikasi daerah kerawanan kebakaran hutan dan lahan menggunakan sistem informasi geografis dan penginderaan jauh di Kawasan Tanjung Jabung Barat Provinsi Jambi. Jurnal Geosains dan Remote Sensing (JGRS), 1(1), 32-42.

Itsnaini, N., Sasmito, B., Sukmono, A., \& Prasasti, I. (2017). Analisis hubungan curah hujan dan parameter peringkat bahaya kebakaran (SPBK) dengan kejadian kebakaran hutan dan lahan untuk menentukan nilai ambang batas kebakaran. Jurnal Geodesi Undip, 6(2), 62-70.

Jawad, A., Nurdjali, B., \& Widiastuti, T. (2015). Zonasi daerah rawan kebakaran hutan dan lahan Di Kabupaten Kubu Raya Provinsi Kalimantan Barat. Jurnal Hutan Lestari, 3(1), 88-97.

Mapilata, E., Gandasasmita, K., \& Djajakirana, G. (2013). Analisis daerah rawan kebakaran hutan dan lahan dalam penataan ruang di Kota Palangkaraya, Provinsi Kalimantan Tengah. Globe, 15(2), 178-184.

Nugroho, P. (2019). Pengembangan model pemetaan daerah rawan kebakaran hutan. Majalah Sawala Edisi 16 No.1/2019 Januari - Juni 2019. 
Nurdiana, A., \& Risdiyanto, I. (2015). Indicator determination of forest and land fires vulnerability using Landsat5 TM data (case study: Jambi Province). Proc Environ Sci, 24(141151).

Nursoleha, P., Banowati, E., \& Parman, S. (2014). Zonasi tingkat kerwaanan kebakaran hutan di Tanam Nasional Gunung Ciremai (TNGC) berbasis sistem informasi geografis (SIG). Geo Image, 3(1), 1-4.

Pamungkas, A.Y. (2020). Prediksi wilayah rawan kebakaran hutan di Provinsi Riau menggunakan metode jaringan saraf tiruan. Thesis Institut Teknologi Sepuluh Nopember.

Paulilin, Y., Tjoneng, A., \& Abdullah. (2017). Pemetaan zona daerah rawan kebakaran hutan dan lahan di Kabupaten Gowa. Jurnal Agrotek, 3(1), 89-97.

Pramesti, D.F., Furqon, M.T., \& Dewi, C. (2017). Implementasi metode $\mathrm{k}$ medoids clustering untuk pengelompokkan data potensi kebakaran hutan/lahan berdasarkan persebaran titik panas (Hotspot). Jurnal Pengembangan Teknologi Informasi dan Ilmu Komputer, 1(9), 723-732.

Rachman, A., Saharja, B., \& Putri, E. (2020). Strategi pencegahan kebakaran hutan dan lahan di Kesatuan Pengelolaan Hutan Kubu Raya, Ketapang Selatan, dan Ketapang Utara di Provinsi Kalimatan Barat. Jurnal Ilmu Pertanian Indonesia (JIPI), 25(2), 213-223.

Rachmawati, N., \& Susilawati. (2012). Upaya masyarakat dalam mencegah kebakaran pada saat pembukaan lahan di Desa Gunung Sari Kecamatan Pulau Laut Utara Kabupaten Kotabaru. Enviroscienteae, 8, 35-44.
Rahman, A. (2016). Peran taruna siaga bencana dalam mitigasi bencana di Kabupaten Serang dan Kabupaten Sukabumi. Jurnal Sosio Konsepsia, 6(01), 56-78.

Rahman, A., \& Yulianti, F. (2018). Mitigasi bencana kebakaran gambut dan pemberdayaan melalui metode restorasi. Jurnal Sosio Informa, 4(2), 448-460.

Septianingrum, R.S. (2018). Dampak kebakaran hutan di Indonesia Tahun 2015. Agric Ecosysim Enviromental.

Solichin., Tarigan, L., Kimman, P., Firman, B., \& Bagyono, R. (2007). Manual pemataan daerah rawan kebakaran South Sumatra Forest Fire Managemant Project (SSFFMP).

Syaufina, L., \& Hafni, D.A. (2018). Variabilitas iklim dan kejadian kebakaran hutan dan lahan gambut di Kabupaten Bengkalis, Provinsi Riau. Jurnal Silvikultur Tropika, 9(1), 6068.

Tata, H., Narendra, \& Mawazin. (2015). Tingkat kerawanan kebakaran gambut di Kabupaten Musi Bantuasin, Sumatera Selatan. Jurnal Penelitian Hutan Tanaman, 14(1), 51-71.

Tata, H., Narendra, B., \& Mawazin. (2018). Forest and land fires in Pelalawan District, Riau, Indonesia: drivers, pressures, impacts and responses. Biodiversitas, 19(2), 544-551.

Viviyanti, R., Adila, T., \& Rahmad, R. (2019). Aplikasi SIG untuk pemetaan bahaya kebakaran hutan dan lahan di Kota Dumai. Media Komunikasi Geografi, 20(2), 78-89.

World Bank. (2015). Krisis kebakaran asam di Indonesia. 